\title{
VALIDATION STUDY OF AIR-SEA GAS TRANSFER MODELING
}

\section{DISCLAIMER}

W. E. Asher

P. J. Farley

I. S. Leifer ${ }^{(n)}$

July 1995
This report was prepared as an account of work sponsored by an agency of the United States Government. Neither the United States Government nor any agency thereof, nor any of their employees, makes any warranty, express or implied, or assumes any legal liability or responsibility for the accuracy, completeness, or usefulness of any information, apparatus, product, or process disclosed, or represents that its use would not infringe privately owned rights. Reference herein to any specific commercial product, process, or service by trade name, trademark, manufacturer, or otherwise does not necessarily constitute or imply its endorsement, recommendation, or favoring by the United States Government or any agency thereof. The views and opinions of authors expressed herein do not necessarily state or reflect those of the United States Government or any agency thereof.

Presented at the

Third International Symposium on Air-Water Gas

Transfer

July 24-27, 1995

Heidelberg, Germany

Prepared for

the U.S. Department of Energy

under Contract DE-AC06-76RLO 1830

Pacific Northwest Laboratory

Richland, Washington 99352

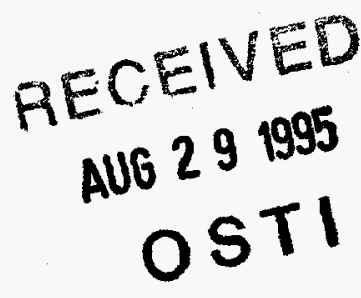

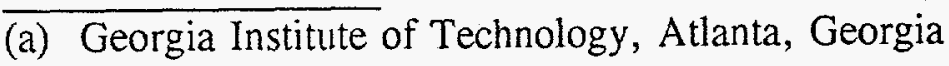




\section{DISCLAIMER}

Portions of this document may be illegible in electronic image products. Images are produced from the best available original document. 
Validation Study of Air-Sea Gas Transfer Modelling

Ira S. Leifer

School of Earth and Atmospheric Sciences, Georgia'Institute of Technology, Atlanta, GA 30332.

William E. Asher and Paul J. Farley

Pacific Northwest Laboratory/Marine Sciences Laboratory, Sequim, WA 98382

Laboratory results have demonstrated the importance of bubble plumes to air-water gas transfer (Asher et al., 1994). Bubble plumes enhance gas transfer by disrupting surface films, by directly transporting a gas, and by the creation of turbulence. Models of bubble gas transfer have been developed by different authors (Atkinson, 1973; Memery and Merlivat, 1985; Woolf and Thorpe, 1991) to determine the magnitude of gas transfer due to bubbles. Laboratory measurements of both the gas transfer rate $\mathrm{k}_{\mathrm{L}}$, and the bubble distribution $\phi$ in a whitecap simulation tank (WST) have allowed these models to be validated and deficiencies in the theoretical assumptions to be explored. Important tests of these models include whether they can explain the experimentally determined solubility and Schmidt number dependency of $\mathrm{k}_{\mathrm{L}}$, predict the time varying bubble concentrations, predict the evasion-invasion asymmetry, and predict the fraction of $\mathrm{k}_{\mathrm{L}}$ due to bubble plumes.

The models tested depend upon the parameterization of the individual bubble gas transfer rate ( $\mathrm{k}_{\mathrm{Bub}}$ ), $\phi$, and for turbulence bubble models, the turbulence scales. The parameterization of $\mathrm{k}_{\mathrm{Bub}}$ depends upon the bubble rise velocity $\left(V_{B}\right)$, and the character of the flow around the bubble. Validation of the models will test the appropriateness of different $k_{\mathrm{Bub}}$ parameterizations, the treatment of turbulence, and the sensitivity of gas transfer to $\phi$.

In the WST, each bucket tip simulates a wave breaking event. The operation of the WST is discussed in Asher and Farley (1995). Measurements of $\phi$ were conducted separately from the $\mathrm{k}_{\mathrm{L}}$ measurements under conditions of dynamic equilibrium. An air-water system is in dynamic equilibrium when the total gas flux into the water from dissolving bubbles is equal to the total gas flux out of the water due to growing bubbles and direct transport through the air-water interface. When the system is far from dynamic equilibrium, bubble growth or dissolution can significantly alter $\phi$ (Asher and Farley, 1995).

Bubble measurements in the WST by phase Doppler anemometry (PDA) provided a time series of the arrival time after a bucket tip, radius, vertical velocity, and one horizontal velocity component of each bubble that crosses the measurement volume. The time series was divided into time segments after each bucket tip and the size segregated bubble concentrations for each time segment were determined according to the method described in Asher and Farley (1995). Repositioning the PDA measurement volume allowed different plume locations to be probed. The distributions thus calculated were combined into a plume bubble concentration distribution $\phi(t, r, x, y, z)$, where $t$ is time, $r$ is radius, and $x, y, z$ are coordinate locations. Because gas transfer is independent of horizontal position in a well mixed fluid, $\phi(t, r, x, y, z)$ was integrated over horizontal position to generate a bubble profile distribution $\phi(t$, $r, z)$ for input into the gas transfer models.

Measurements of bubble concentration for $z<10 \mathrm{~cm}$ were not possible due to interference by surface waves and $\phi(t, r, z)$ for $z<10 \mathrm{~cm}$ was extrapolated from measurements within the plume $(\mathrm{z}<35 \mathrm{~cm})$. A least squares fit at each radius and time to the $\log (\phi(z))$ was used to extrapolate to shallower depths. In the configuration used, the smallest radius that concentrations could reliably be calculated from the PDA measurements was 50 microns (Asher and Farley, 1995). Bubble concentrations to a radius of 20 microns were extrapolated from a least squares fit of $\log (\phi(r))$ for bubbles (75 microns $<r<115$ microns) at each time and depth within the plume. Outside the plume, $\phi(r)$ rather than the $\log (\phi(r))$ was used. The depth extrapolation was conducted on $\phi(t, r, z)$ as opposed to $\phi(t, r, x, y$, z) to obtain better statistics. 
Wave breaking produces strong turbulent mixing that is inhomogeneous and non-stationary. In the current treatment, the turbulence velocity, length, and time scales $\left(\mathrm{V}_{\mathrm{T}}, \mathrm{L}_{\mathrm{T}}, \mathrm{T}_{\mathrm{T}}\right)$ were estimated as their time and spatially averaged values. It was assumed that turbulence effects only bubble transport, not $\mathrm{k}_{\mathrm{Bub}}$. This is equivalent to assuming that eddies with $a \mathrm{~L}_{\mathrm{T}}$ on the order of the radius of those bubbles important to gas transfer are viscously dissipated.

Bubbles were modeled as being transported by eddies with scales $\mathrm{V}_{\mathrm{T}}, \mathrm{L}_{\mathrm{T}}$ and $\mathrm{T}_{\mathrm{T}}$ in a direction $\alpha$, where $\alpha$ was defined with respect to the vertical axis. Excluding buoyant rise, the bubbles remained embedded in the flow of each eddy for an average time period $\mathrm{T}_{\mathrm{T}}$ before entering a new eddy. A turbulence velocity time series simulated this process by randomly picking a new $\alpha$ after $T_{\mathrm{T}}$ seconds. The vertical velocity component of the turbulence velocity time series was smoothed by spline interpolation to prevent numerical instability. A new turbulence velocity time series was calculated each tip cycle.

An estimate was made of $V_{T}$ by comparing model predicted $\phi(t, r, z)$ with experimentally measured $\phi(t, r$, z). Large bubbles with $V_{B}>V_{T}$ were relatively unaffected by eddies while the trajectories of bubbles with $V_{B} \leq V_{T}$ were significantly altered. A comparison of model predicted $\phi(t, r, z)$ under conditions of no-turbulence and dynamic equilibrium with experimentally measured $\phi(t, r, z)$ showed good agreement for bubbles with $V_{B}>\sim 4 \mathrm{~cm} / \mathrm{sec}$ and poor agreement for bubbles with $V_{B}<-2 \mathrm{~cm} / \mathrm{sec}$. Subsequent turbulence model predicted $\phi(t, r, z)$ were improved for $V_{T}=2-4 \mathrm{~cm} / \mathrm{sec}$ relative to predicted $\phi(t, r, z)$ for $V_{T}<2 \mathrm{~cm} / \mathrm{sec}$ and $V_{T}>4 \mathrm{~cm} / \mathrm{sec}$, supporting an estimate of $V_{\mathrm{T}}=3 \mathrm{~cm} / \mathrm{sec}$.

The values of $\mathrm{V}_{\mathrm{T}}, \mathrm{T}_{\mathrm{T}}$, and $\mathrm{L}_{\mathrm{T}}$, were calculated from PDA velocity measurements which provides a randomly varying sample-time series of bubble velocities. After accounting for buoyancy, linearly interpolating to a uniform time series, and high-pass filtering to remove waves and edge effects from the interpolation, standard turbulence velocity analysis techniques were applied to calculate $\mathrm{V}_{\mathrm{T}}, \mathrm{L}_{\mathrm{T}}$, and $\mathrm{T}_{\mathrm{T}}$. Comparison with modeling results will test the appropriateness of the application of standard turbulence velocity analysis techniques.

Four different models were tested, a steady state model (Atkinson, 1973), ATK, a non-turbulence model with constant bubble radius (Memery and Merlivat, 1985), MM, a turbulence model with constant bubble radius (Woolf and Thorpe, 1991), WT, and a turbulence model with varying bubble radius, ISL.

The ATK model calculated the gas flux for each bubble in the time average $\phi(r, z)$ with no bubble motion or change in bubble gas phase composition. The $\mathrm{k}_{\mathrm{Bub}}$ parameterization used was the stagnant flow solution (Clift et al., 1978). The equations describing steady state gas transfer include the effect of hydrostatic pressure and surface tension. The model calculated the bubble contribution to $\mathrm{k}_{\mathrm{L}}$ from the total gas fluxed during a bucket tip cycle.

The MM model calculated the gas flux for each bubble in an injection distribution $\phi_{i}(r, z)$, which buoyantly rises to the surface from its injection depth. The $\phi_{\mathrm{i}}(r, z)$ is the maximum bubble concentration and was calculated from $\phi(t, r, z)$ at $t=2 \mathrm{sec}$. Although $\phi(t, r, z)$ for $t<2 \sec$ may be larger than $\phi_{\mathrm{i}}(r, z)$, PDA measurements were unavailable, and the $\mathrm{t}<2 \mathrm{sec}$ contribution to gas transfer was assumed small. The injected bubble's initial gas phase composition was atmospheric and evolved as the bubbles transferred gas. The coupled differential equations describing bubble gas transfer with constant radius were solved numerically with a standard fourth order Runge-Kutta routine for each bubble in $\phi_{i}(r, z)$. The kBub parameterization used was as in Memery and Merlivat (1985) for clean bubbles. From $\phi_{i}(r, z)$ and the total gas fluxed by each bubble the model calculated the total gas transferred by the bubble plume, the predicted $\phi(t, r, z)$, and the plume contribution to $\mathrm{k}_{\mathrm{L}}$.

The WT model calculated the gas flux for each bubble in $\phi_{\mathrm{i}}(\mathrm{r}, \mathrm{z})$ which in addition to buoyant rise are advected by a turbulence velocity component. The coupled differential equations describing bubble gas transfer were solved as discussed above, for both dirty and clean bubbles. The $k_{B}$ ub parameterization was calculated as in Woolf and Thorpe (1991) based on $V_{B}$, under the assumption that bubbles are embedded in the turbulence flow. From $\phi_{i}(t$, 
z) and the total gas fluxed by each bubble, the model calculated the total gas transferred by the bubble plume, the predicted $\phi(t, r, z)$, and the plume contribution to $k_{L}$.

The ISL model is similar to the WT model except that the coupled differential equations describing bubble gas transfer include radius variations. The $\mathrm{k}_{\mathrm{Bub}}$ parameterization was calculated as above using the parameterization of Clift et al. eqn 5-37, (1978). From $\phi_{\mathrm{i}}(\mathrm{t}, \mathrm{z})$ and the total gas fluxed by each bubble, the model calculated the total gas transferred by the bubble plume, the predicted $\phi(t, r, z)$, and the plume contribution to $\mathrm{k}_{\mathrm{L}}$.

All models simulated multiple bucket tip cycles. The two turbulence models were run for sufficient tip cycles to generate statistically significant number of eddies $(\#>50)$ for bubbles affected by turbulence $\left(V_{B} \leq V_{T}\right)$, found to be at least four tip cycles. The models allowed up to nine gases simultaneously and were run under different conditions of trace and major gas concentrations and partial pressures.

This research was supported by the U.S. Department of Energy (DOE) under contract DE-AC06-76RLO 1830. Pacific Northwest Laboratory is operated for DOE by Battelle Memorial Institute.

\section{References}

Asher, W. E., P. J. Farley, B. J. Higgins, L. M. Karle, I. S. Leifer and E. C. Monahan, 1994, "The Influence of Bubble Plumes on Air-Sea Gas Exchange", EOS Nov. 1 supplement 75 : (44) 369.

Asher, W. E. and P. J. Farley, 1995, "Phase-Doppler Anemometer Measurement of Bubble Concentrations in Laboratory-Simulated Breaking waves", Accepted in Journal of Geophysical Research, Oceans.

Atkinson, L. P., 1973, "Effect of Air Bubble Solution on Air-Sea Gas Exchange", Journal of Geophysical Research 78: 962-968.

Clift R., Grace J. R. and M. E. Weber, 1978, Bubbles. Drops and Particles, Academic Press, NY.

Memery, L. and L. Merlivat, 1985, "Modeling of the Gas Flux Through Bubbles at the Air-Water Interface", Tellus $37 B: 272-285$.

Woolf, D. K. and S. A. Thorpe, 1991, "Bubbles and the Air-Sea Exchange of Gases in Near Saturation Conditions", Journal of Marine Research 49 : 435-466. 